\title{
Storage Technologies to Enhance Longevity in Paddy (Oryza sativa L.) Seed of Parental Lines IR58025A and IR58025B of Hybrid PRH-10
}

\author{
Anuja Gupta \\ Indian Agricultural Research Institute, Regional Station, Karnal - 132 001, Haryana, India. \\ E-mail: agupta_2005@yahoo.com
}

\begin{abstract}
Storage conditions, storage containers and seed treatments prior to storage are important factors responsible for retaining seed longevity. But ideal storage environment are seldom available for the precious seed, especially under tropical conditions. Maintenance of seed germination in vulnerable parental lines IR 58025A (6A) and IR 58025B (6B) of paddy (Oryza sativa L.) during storage was investigated using integration of different treatments as storage containers (jute bags/ polylined jute bags), storage conditions (ambient/LTLH i.e. low temperature, low humidity or controlled) and seed dressings (captan/thiram) at Karnal seed godowns in North India during 2000-2007. Ten $\mathrm{kg}$ of seed was stored per treatment. Seed was taken from the fields of Indian Agricultural Research Institute, Regional Station, Karnal (India). The initial moisture content of paddy seeds was kept $13 \%$ which is a standard. The results revealed that there was significant difference in the storability of paddy seeds under different storage conditions. Under LTLH storage conditions (temperature:15 ${ }^{\circ} \mathrm{C}$ and relative humidity:30\%) paddy seeds maintained germination above the minimum seed certification standards $(80 \%)$ up to 60 months after seed treatment as against 24 months when stored under ambient conditions. The germination of seeds stored under LTLH conditions $(86.1 \%)$ and in polylined jute bags $(75.3 \%)$ was significantly higher than seeds stored under ambient condition $(61.9 \%)$ and in jute bags $(72.8 \%)$ after 60 months of seed treatment. Treatment with thiram/captan also showed improved seed germination by $7 \%$ as against untreated control. Seed vigour also followed a trend similar to seed germination. The incidence of seed mycoflora was $54.8 \%$ and $45.2 \%$ in seeds of $6 \mathrm{~A}$ and $6 \mathrm{~B}$, respectively. This was significantly higher in seeds stored under LTLH conditions (62.1\%) and in jute bags $(39.1 \%)$ compared to seeds stored under ambient condition (64.7\%) and in polylined jute bags (47\%). In all 16 fungi were found associated with paddy seeds. However, the fungal incidence in treated seeds was $29.2 \%$ as against $70.8 \%$ in untreated control. Seed moisture content did not vary much amongst different treatments though it was higher in seeds stored under ambient storage conditions $(11.7 \%)$ as against seeds stored under LTLH- low temperature, low humidity conditions $(9.2 \%)$.
\end{abstract}

Keywords: Paddy-Rice; Seed Germination; Seed Mycoflora; Seed Storage; Storage Condition

\section{Introduction}

The germination of paddy varieties in storage does not suffer much as compared to other cereals (Paderes, et al., 1997). However, paddy seed stored for long- term is invariably exposed to climatic adversities e.g. extreme summer, winter and monsoons and requires a great deal of effort to safeguard it. There is hardly any recommendation available to maintain seed quality during storage. The breeders engaged in hybrid rice research also confront germination problem associated with the parental lines especially with one of the male sterile parent 6A. This parent loses its viability at fast rate when in storage and poses the problem of poor germination at the time of next sowing season.

Seed deterioration during storage is a gradual and inevitable process causing considerable losses. Seeds tend to lose viability and vigour during storage and information on storability of seed lots from harvest until the next planting season and also for carry over purposes is of immense importance in any seed production programme. Availability of good quality seed of parental lines is essential for any successful hybrid seed production. Seed mycoflora has been recognized as an important factor responsible for deterioration in quality of seeds during storage (Gupta and Aneja 2001). Hence, an understanding of how best these seeds can be stored at a relatively low cost with minimal deterioration in quality for periods extending over one, two or more seasons will be of great interest to the seed industry. Seed longevity depends upon a number of factors such as the genetic constitution, initial seed quality, storage environment, packaging material and pre-storage seed treatments. It has been ascertained (Gupta 2003; Jakhar et al., 2003) that pre-storage treatments protect the seed from microbial infestation and also enhance the storage potential of seeds. The present study was undertaken to prolong or sustain the seed longevity in parental lines of paddy by pre-storage seed dressings and interaction thereof with storage containers and storage environments.

Rice is by far the most important food crop in many developing countries, providing two-thirds of calorie intake of more than 3 billion people in Asia, and onethird of the calorie intake of nearly 1.5 billion people in Africa and Latin America (FAO, 1995). Approximately $11 \%$ of the world arable land is planted annually to rice (Chakravarthi and Naravaneni, 2006).

Postharvest operation methods have strong effects on seed quality. The main purpose of seed storage is to secure the supply of good quality seed for planting program whenever needed. Hence, seeds must often be stored during the period from harvest to sowing. The 
storage time could be short-term (less than a year) or long- term (more than a year) (Perry, 1978).

The main constraints in seed storage are high temperature and moisture which affect the maintenance of seed quality in storage. High temperature and moisture favour the development of insects, bacteria and fungi. Storage structures and practices should also protect the seed against damage by rodents. Storage structures for food are often designed for the same purpose.

Traditional storage structures, such as those using mud walls or underground spaces, are often well-designed and provide efficient isolation to keep temperatures moderately low. Ideally airtight containers are used to store well-dried seed (Greve and Van, 1983). In some countries $50 \mathrm{~kg}$ capacity bags of laminated polythene/aluminum foil are available; in other areas, multi-layer polythene-lined oil drums are used. Airtight containers also solve possible insect problems because the insects suffocate as soon as oxygen in the container is used up (Thijssen et al., 2008).

In situations when the storage season is warm and humid it is extremely important that seed lots in airtight containers should be dried very well before the container is closed for fear of respiration, thus increasing the relative humidity in the container. A seed lot of high seed vigour will produce greater percentage of seedling than a low vigour lot. The rate and uniformity of germination and emergence are also included among the vigour characters.

Assuming a good storage environment, the most practical way to further extend the storage life of seeds is to begin with seed of the highest possible vigour. Seed storage reduces vigour more than viability. The danger in long term storage is subtle that damage can occur to the seed which is undetectable by germination tests under favourable conditions. This is dangerous for sowing purpose since the ability of the seed to resist stress is impaired. Factors affecting seed vigour include genetic background, the process of seed development, and handling during harvest and storage conditions and length (Bhaskaran et al., 2005).

Seed health testing is important for three reasons (1) seed-borne inoculums may give rise to progressive disease development in the field and reduce commercial value of the crop, (2) imported seed lots may introduce disease into new regions, and (3) the disease may attack seedlings, and causes poor germination or field establishment (Fairey and Hampton, 1997).

Some microorganisms associated with seeds either as saprophyte or pathogens promote seed rot and reduce germination while others may cause destruction in storage. Seed health testing can, therefore, check on the effects of seed-borne diseases and can supply an important measure of overall seed quality and control of crop diseases. Seeds can serve as vehicles for dissemination of plant pathogens, which can result in disease outbreaks.

The present study was undertaken to prolong or maintain the seed longevity in parental lines of paddy by pre-storage treatments and interaction thereof with containers and storage environments.

\section{Materials and Methods}

Freshly harvested seeds of parental lines of paddy IR58025A (6A) and IR 58025B (6B) were obtained and sampled. Two samples of each parent were treated with fungicides thiram/ captan as dry dressing @ $2.5 \mathrm{~g} / \mathrm{kg}$ seed, respectively, and the third sample was left untreated which served as control. Four sub- samples of each treatment were prepared and two sub- samples were kept in jute bag and the other two were put in polylined jute bag (polythene bag of 400 gauge inside a jute bag) for each parental line and sealed and closed. One set of seed samples was stored under controlled or low temperature low humidity (LTLH) conditions and the other set was stored under ambient conditions in seed godowns at Karnal in North India. Treatments were in completely randomized design in replications. Initial record on seed germination, seed moisture, seed vigour and seed mycoflora was recorded and subsequent record were taken at bimonthly intervals up to 60 months of storage after seed treatment. For seed germination, the $100 \times 4$ seeds were tested in "between paper" (B.P) substrata at $25{ }^{\circ} \mathrm{C}$ temperature by keeping in seed germinator as per ISTA (1999). For seed moisture determination, the paddy seeds were determined by hot air oven method. Ground material and was kept at $130{ }^{\circ} \mathrm{C}$ temperature for 2 hours in hot air oven. For seed vigour test the seed vigour Index I was determined by the following formula (AbdulBaki and Anderson, 1973)

Seed vigour Index I = Standard germination $\mathrm{x}$ shoot + root length $(\mathrm{cm})$.

For seed mycoflora, the seeds were planted on specific medium after treatment with 1-2\% sodium hypochlorite $(\mathrm{NaOCl})$ and incubated. The fungi were identified based on colony characteristics using compound microscope. For seedling emergence for different treatments was determined in the field during the Kharif season in three consecutive years by the following formula (Maguine, 1962):

$\underline{\text { Seedling emergence on first count }}+\underline{\text { Seedling emerged at final count }}$ Number of days planted $\quad+\quad$ Number of days at final count

The collected data were statistically analyzed as per CRD. Different types of software were used.

\section{Results and Discussion}

\subsection{Environmental Conditions During Storage}

The minimum temperature of the seed godown under ambient conditions varied from 16.1 to $33.6^{\circ} \mathrm{C}$ and the maximum temperature varied from 17.1 to $34.8{ }^{\circ} \mathrm{C}$. The relative humidity for the corresponding period varied from a minimum of $35.9 \%$ to a maximum of $75.5 \%$. Under controlled conditions, temperature and relative humidity of the seed godown was maintained at $15^{\circ} \mathrm{C}$ and $30 \%$, respectively. 
Anuja Gupta

\subsection{Seed Germination}

Seed germinability of the rice cultivars was not affected significantly up to a period of 24 months by the storage condition, storage containers or seed treatments (Table 1). The germination of seeds of both the parental lines stored under LTLH conditions remained above the acceptable levels $(>80 \%)$ up to 60 months of storage after seed treatment and 64 months of storage after seed harvest, irrespective of treatments. Highest germination $(87.8 \%)$ was recorded in treated seeds packed in polylined jute bags and stored under LTLH conditions on 60 months of storage after seed treatment. The germination of seeds stored under ambient conditions could be maintained above minimum seed certification standard (MSCS) up to 24 months of storage only. However,
Storage Technologies to Enhance Longevity

seeds treated with thiram/captan retained more than $83 \%$ seed germination up to 28 months, irrespective of storage containers and on further storage the germination in the seeds stored under ambient conditions declined below MSCS but the germination of seeds stored under LTLH conditions remained above $80 \%$, irrespective of storage containers / seed treatments. Maximum decline in seed germination was observed in the untreated seed lots stored in jute bags under ambient storage conditions. The germination of seeds stored under LTLH conditions $(86.1 \%)$ and in polylined jute bags $(75.3 \%)$ was significantly higher than seeds stored under ambient condition $(61.9 \%)$ and in jute bags $(72.8 \%)$ after 60 months of seed treatment.

Table 1. Effect of storage conditions, storage containers and seed treatments on germination (\%) of paddy seed.

\begin{tabular}{|c|c|c|c|c|c|c|c|c|c|c|c|}
\hline \multirow{2}{*}{$\begin{array}{l}\text { Storage } \\
\text { condition }\end{array}$} & \multirow{2}{*}{$\begin{array}{l}\text { Storage } \\
\text { container }\end{array}$} & \multirow{2}{*}{$\begin{array}{l}\text { Seed } \\
\text { treatment }\end{array}$} & \multicolumn{9}{|c|}{ Storage duration (months) } \\
\hline & & & 0 & 8 & 12 & 16 & 24 & 28 & 36 & 48 & 60 \\
\hline \multirow[t]{4}{*}{ Ambient } & Jute bag & Treated ${ }^{*}$ & $86.1 \mathrm{a}$ & $90.8 \mathrm{~b}$ & $86.9 \mathrm{a}$ & $90.3 \mathrm{~b}$ & $89.9 \mathrm{c}$ & $83.3 \mathrm{~b}$ & $42.5 \mathrm{e}$ & $0.9 \mathrm{e}$ & $0.0 \mathrm{c}$ \\
\hline & Jute bag & Untreated & $81.8 \mathrm{c}$ & $88.0 \mathrm{~d}$ & $82.4 \mathrm{~b}$ & $82.5 \mathrm{e}$ & $75.4 \mathrm{f}$ & $61.9 \mathrm{~d}$ & $29.5 \mathrm{f}$ & $0.1 \mathrm{e}$ & $0.0 \mathrm{c}$ \\
\hline & Polylined bag & Treated & $86.6 \mathrm{a}$ & $91.2 \mathrm{~b}$ & $89.1 \mathrm{a}$ & $93.0 \mathrm{a}$ & $90.2 \mathrm{bc}$ & $83.8 \mathrm{~b}$ & $69.6 \mathrm{c}$ & $12.9 \mathrm{c}$ & $0.0 \mathrm{c}$ \\
\hline & Polylined bag & Untreated & $82.6 \mathrm{c}$ & $86.9 \mathrm{~d}$ & $81.9 \mathrm{bc}$ & $82.8 \mathrm{e}$ & $82.4 \mathrm{e}$ & $71.0 \mathrm{c}$ & $50.5 \mathrm{~d}$ & $4.4 \mathrm{~d}$ & $0.0 \mathrm{c}$ \\
\hline \multirow[t]{5}{*}{ LTLH } & Jute bag & Treated & $86.4 \mathrm{a}$ & $91.0 \mathrm{~b}$ & $87.5 \mathrm{a}$ & $90.5 b$ & $94.1 \mathrm{a}$ & $83.9 \mathrm{~b}$ & $82.4 \mathrm{a}$ & $88.0 \mathrm{a}$ & $82.0 \mathrm{~b}$ \\
\hline & Jute bag & Untreated & $83.8 \mathrm{bc}$ & $89.3 c$ & $83.4 \mathrm{~b}$ & $88.1 \mathrm{c}$ & $90.3 \mathrm{bc}$ & $83.5 b$ & $76.8 \mathrm{~b}$ & $84.5 b$ & $80.6 \mathrm{~b}$ \\
\hline & Polylined bag & Treated & $85.5 \mathrm{ab}$ & $92.5 \mathrm{a}$ & $88.2 \mathrm{a}$ & $88.8 b c$ & $92.2 \mathrm{ab}$ & $87.9 \mathrm{a}$ & $84.8 \mathrm{a}$ & $87.0 \mathrm{a}$ & $87.8 \mathrm{a}$ \\
\hline & Polylined bag & Untreated & $83.5 \mathrm{bc}$ & $91.1 \mathrm{~b}$ & $80.0 \mathrm{c}$ & $84.8 \mathrm{~d}$ & $87.9 \mathrm{~d}$ & $83.9 \mathrm{~b}$ & $82.3 a$ & $83.5 b$ & $80.3 \mathrm{~b}$ \\
\hline & LSD 0.01 & & $2.8^{* * *}$ & $1.5^{* * *}$ & $3.0^{* * *}$ & $2.6^{* * *}$ & $2.7^{* * *}$ & $4.4^{* * *}$ & $5.1^{* * *}$ & $2.6^{* * *}$ & $3.4^{* * * *}$ \\
\hline
\end{tabular}

* Seed treated with Thiram or Captan @ $2.5 \mathrm{~g} / \mathrm{kg}$ seed

Amongst the two parental lines, seeds of 6B (IR 58025B) maintained about $3 \%$ higher seed germination at all storage intervals than 6A (IR 58025A), irrespective of treatments (Figure 1). The results also revealed about 40 percent increase in germination when the seeds were stored under LTLH conditions as against seeds stored under ambient conditions. Similarly, $3 \%$ and $7 \%$ increase in germination was observed in seeds packed in polylined jute bags and in treated seeds over seeds packed in jute bags and untreated seeds, respectively.

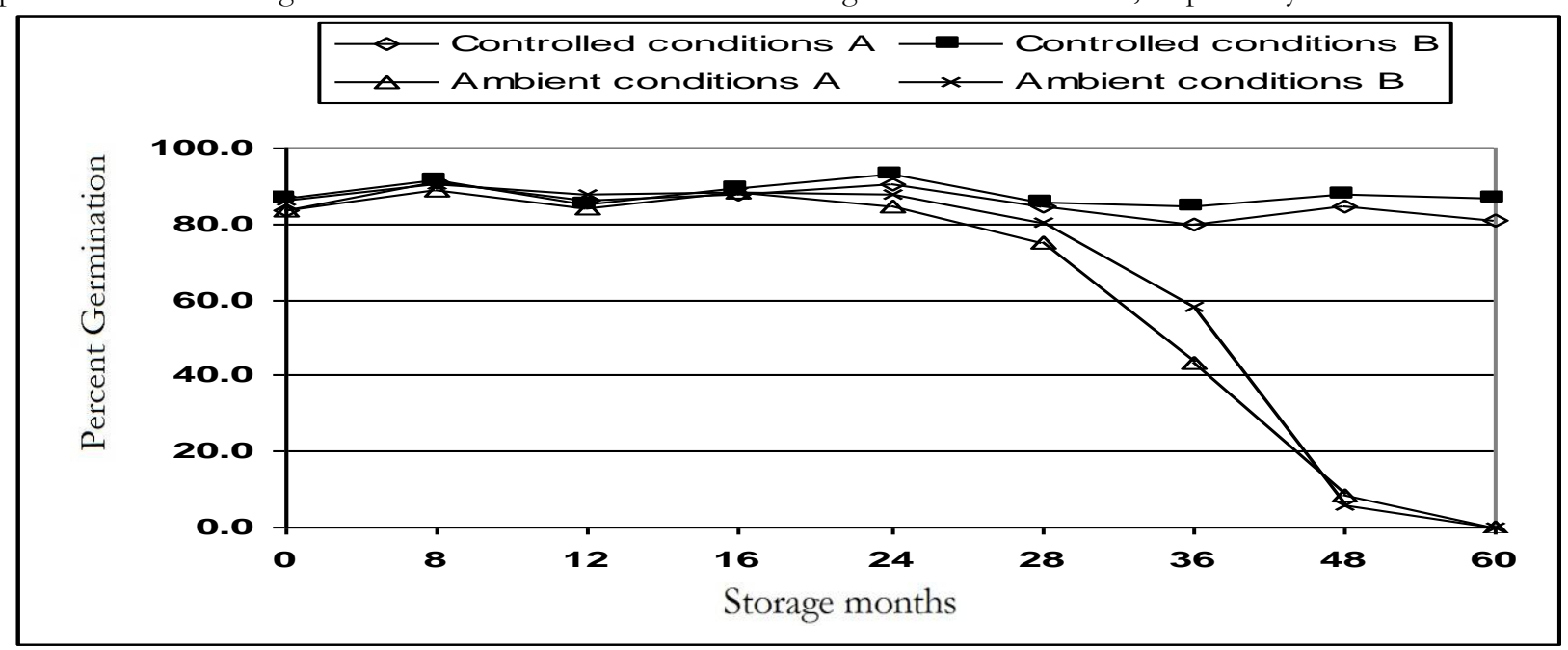

Figure 1. Effect of storage conditions on seed germination in parental lines of Paddy during storage.

The effect of two storage containers on seed germination was insignificant during early period of storage up to 24 months but on further storage about 4 percent higher germination was recorded in seeds stored in polylined bags as against in seeds stored in jute bags (Figure 2).
Freire and Mumford (1986) also observed rapid deterioration of seeds in permeable containers as against hermetically sealed laminated aluminum foil packages and metal cans. 


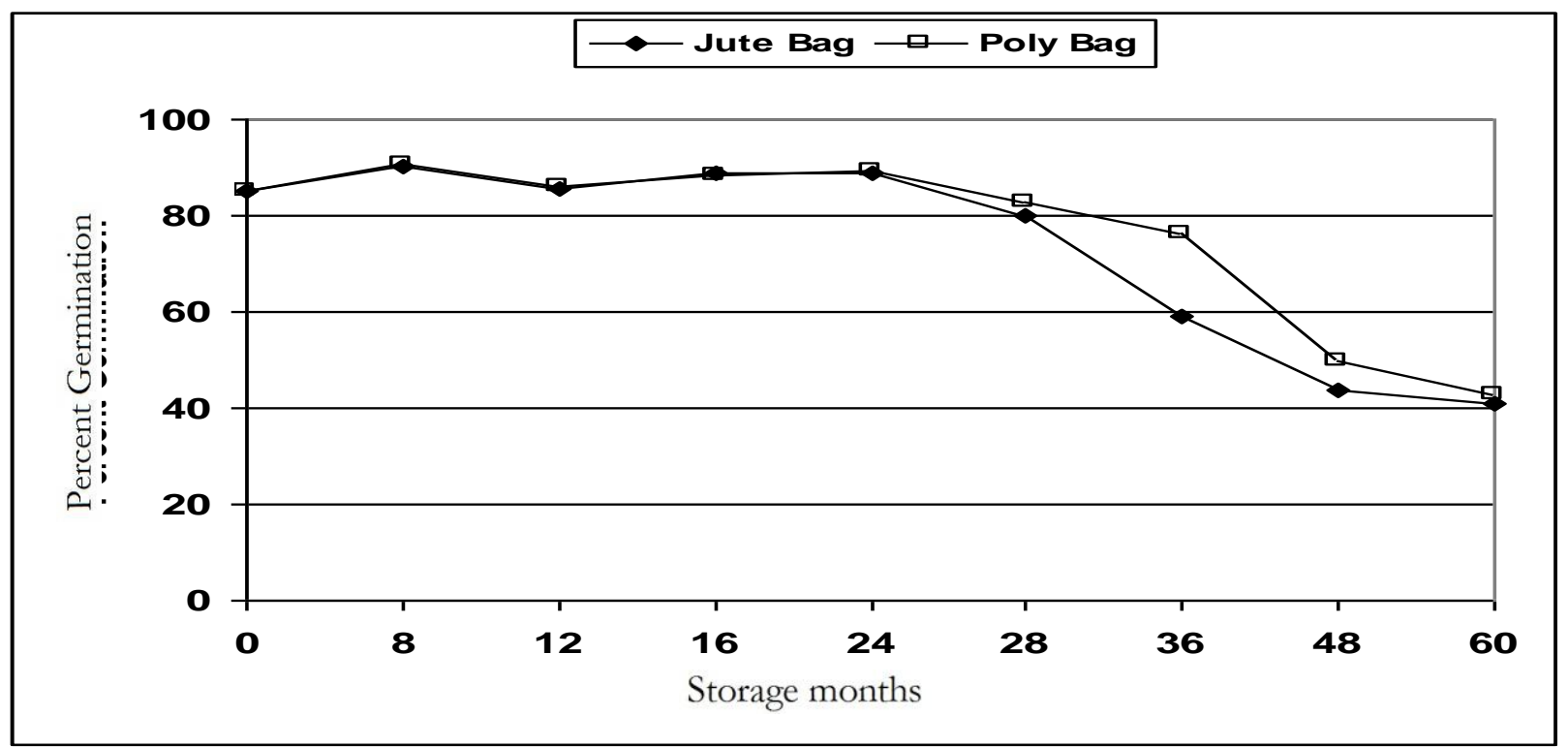

Figure 2. Effect of storage containers on seed germination in parental lines of Paddy during storage.

The effect of seed dressings on germination percentage of paddy seeds was apparent at all storage intervals (Figure 3). Germinability of treated seeds was significantly higher than untreated seeds at all storage intervals up to 28 and 60 months under ambient months and LTLH storage conditions, respectively. Though germination of paddy seed stored under LTLH conditions was above MSCS irrespective of storage containers but higher germination was recorded in treated seed as against untreated seed stored in same type of container. Both thiram and captan seed dressings were equally effective in maintaining seed germination. Thus, storage of seeds in polylined containers and under controlled conditions was superior to storage of seeds in jute bags and under ambient conditions, respectively, especially at later storage period.

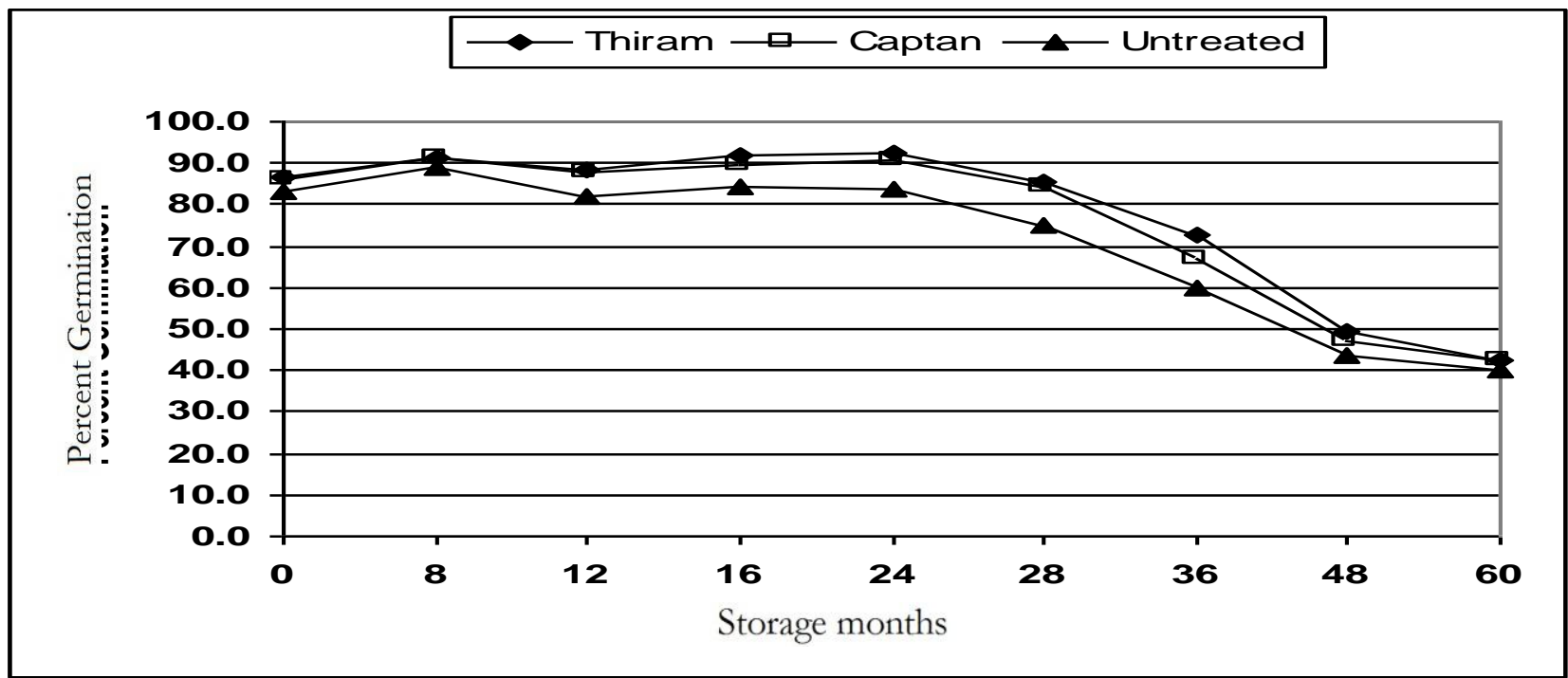

Figure 3. Effect of seed treatments on seed germination in parental lines of paddy during storage.

\subsection{Seed Vigour}

Seed vigour also followed a trend similar to seed germination, i.e., it increased with the storage duration up to 24 months and then declined before the fall in seed germination ?? (Table 2). Comparatively higher seed vigour was recorded in seeds of 6B (1528.0) than in seeds of $6 \mathrm{~A}$ (1496.0); in seeds stored in polylined containers
(1241.6) than in seeds stored in jute bags (1167.9); in treated seeds (1275.8) as against untreated seeds (915.4) and in seeds stored under LTLH environment (1424.0) than in seeds stored under ambient conditions (985.5). Treated seeds showed $28.3 \%$ higher seed vigour than untreated seeds during storage. About 18\% increase in 
Anuja Gupta

seed vigour was also recorded in seeds stored under controlled conditions as against seed stored under ambient conditions and 5.9\% increase in seed vigour was recorded in seeds stored in polylined bags as against jute bags.

The superiority of fungicide treatments and polylined containers for maintenance of viability of hybrid seed has also been confirmed by Jakhar et al. (2003). They reported that non-systemic fungicides were more effective than systemic fungicides in maintaining viability of pearl millet seeds during storage.

Amongst deteriorative changes, membrane degradation has been proposed as the primary event in ageing (Dadlani and Agarwal, 1983). But paddy seed has a husk covering thereby protecting the seed under adverse conditions and hence the rate of deterioration in paddy seed though is low but it is important to save the precious seed against deterioration.

Agarwal (1980) observed that leaching of sugars declined during storage of paddy cultivars, which was maximum after 6-8 months of storage but minimum after 22 months of storage because during storage soluble
Storage Technologies to Enhance Longevity

sugars in seeds decreased. They also observed less leakage of water soluble sugars and amino acids in cooler months than in warmer months. The conductivity of seed leachates increased about two-folds during storage for soybean cultivars (Trawatha et al., 1995). Hence, storage under LTLH conditions restricts the metabolic activity of seeds and thereby leaching of solutes. Gupta and Aneja (2004) also observed leaching of solutes to be inversely correlated to seed germination in soybean seeds. The longevity of pearl millet seeds could also be prolonged two-folds when the seeds were stored under LTLH conditions (Gupta, 2007).

Seeds of different cultivars of paddy treated with thiram also recorded $9.96 \%$ and $13.04 \%$ increase in seed germination and seed vigour, respectively over untreated. The enhancement in germination and vigour observed in fungicide treated seeds on stored seeds are in agreement with the results of the studies undertaken by Mishra and Dharamvir (1991) and Sachan and Agarwal (1994). However, Kauraw (1986) observed adverse effect of fungicide dressings on the shoot and root length of the seedlings.

Table 2. Effect of storage conditions, storage containers and seed treatments on vigour of paddy seed.

\begin{tabular}{|c|c|c|c|c|c|c|c|c|}
\hline \multirow{2}{*}{$\begin{array}{l}\text { Storage } \\
\text { condition }\end{array}$} & \multirow{2}{*}{$\begin{array}{l}\text { Storage } \\
\text { container }\end{array}$} & \multirow{2}{*}{$\begin{array}{l}\text { Seed } \\
\text { treatment }\end{array}$} & \multicolumn{6}{|c|}{ Storage duration (months) } \\
\hline & & & 0 & 12 & 24 & 36 & 48 & 60 \\
\hline \multirow[t]{4}{*}{ Ambient } & Jute bag & Treated ${ }^{*}$ & $1451.8 \mathrm{a}$ & $1526.4 \mathrm{a}$ & $1597.4 \mathrm{c}$ & $580.1 \mathrm{e}$ & $7.2 \mathrm{c}$ & $0.0 \mathrm{c}$ \\
\hline & Jute bag & Untreated & $1355.9 \mathrm{~b}$ & 1121.6e & $1304.0 \mathrm{~d}$ & $389.5 \mathrm{f}$ & $1.1 \mathrm{c}$ & $0.0 \mathrm{c}$ \\
\hline & Polylined bag & Treated & $1469.2 \mathrm{a}$ & $1467.2 \mathrm{ab}$ & $1565.3 \mathrm{c}$ & $935.8 \mathrm{c}$ & $179.0 \mathrm{~b}$ & $0.0 \mathrm{c}$ \\
\hline & Polylined bag & Untreated & $1297.2 b$ & $1362.5 \mathrm{bc}$ & $1403.2 \mathrm{~d}$ & $745.8 \mathrm{~d}$ & $46.0 \mathrm{c}$ & $0.0 \mathrm{c}$ \\
\hline \multirow[t]{5}{*}{ LTLH } & Jute bag & Treated & $1456.0 \mathrm{a}$ & $1293.5 \mathrm{~cd}$ & $1748.7 \mathrm{ab}$ & $1466.5 \mathrm{a}$ & $1744.7 \mathrm{a}$ & $1201.5 b$ \\
\hline & Jute bag & Untreated & $1294.1 b$ & $750.9 \mathrm{~g}$ & $1634.2 \mathrm{bc}$ & $1313.8 b$ & $1718.5 \mathrm{a}$ & $1321.6 a$ \\
\hline & Polylined bag & Treated & $1325.2 b$ & 1156.9de & $1816.0 \mathrm{a}$ & $1503.3 \mathrm{a}$ & $1730.2 \mathrm{a}$ & $1358.3 a$ \\
\hline & Polylined bag & Untreated & $1191.5 c$ & $956.4 \mathrm{f}$ & $1749.3 \mathrm{ab}$ & $1435.5 \mathrm{a}$ & $1662.3 \mathrm{a}$ & $1347.9 \mathrm{a}$ \\
\hline & LSD 0.05 & & $87.9^{* * *}$ & $136.8^{* * *}$ & $114.4^{* * *}$ & $74.5^{* * *}$ & $80.8^{* * *}$ & $117.2^{* * *}$ \\
\hline
\end{tabular}

\subsection{Seed Moisture}

The moisture content of seeds did not vary much amongst the two parental lines $6 \mathrm{~A}(10.6 \%)$ and $6 \mathrm{~B}$ $(10.3 \%)$. Amongst the seed dressings, it was 10.5 and $10.3 \%$ in treated and untreated seed, respectively. However, the moisture content of seed packed in jute bag varied from 7.8 to $13.7 \%$ (average $10.7 \%$ ) as against 7.8 to $12.9 \%$ (average $10.1 \%$ ) moisture in seed packed in polylined bag (Figure 4). However, higher variation in the moisture content was recorded in seeds stored under ambient conditions (7.8-13.7\%; average $11.7 \%$ ) as against moisture content of seed stored under LTLH conditions (7.8-11.1\%: average 9.2\%). Under LTLH conditions, the moisture content appeared more stable and did not exhibit much variation. Increase in the moisture content of seeds stored under ambient conditions probably is an important factor responsible for early decline of seed germinability. Earlier studies by Gupta (2003) reported negative correlation between seed longevity and seed moisture in stored soybean seeds. Gowda and Bhole (1989) had also observed variability in seed viability due to different storage environments. 

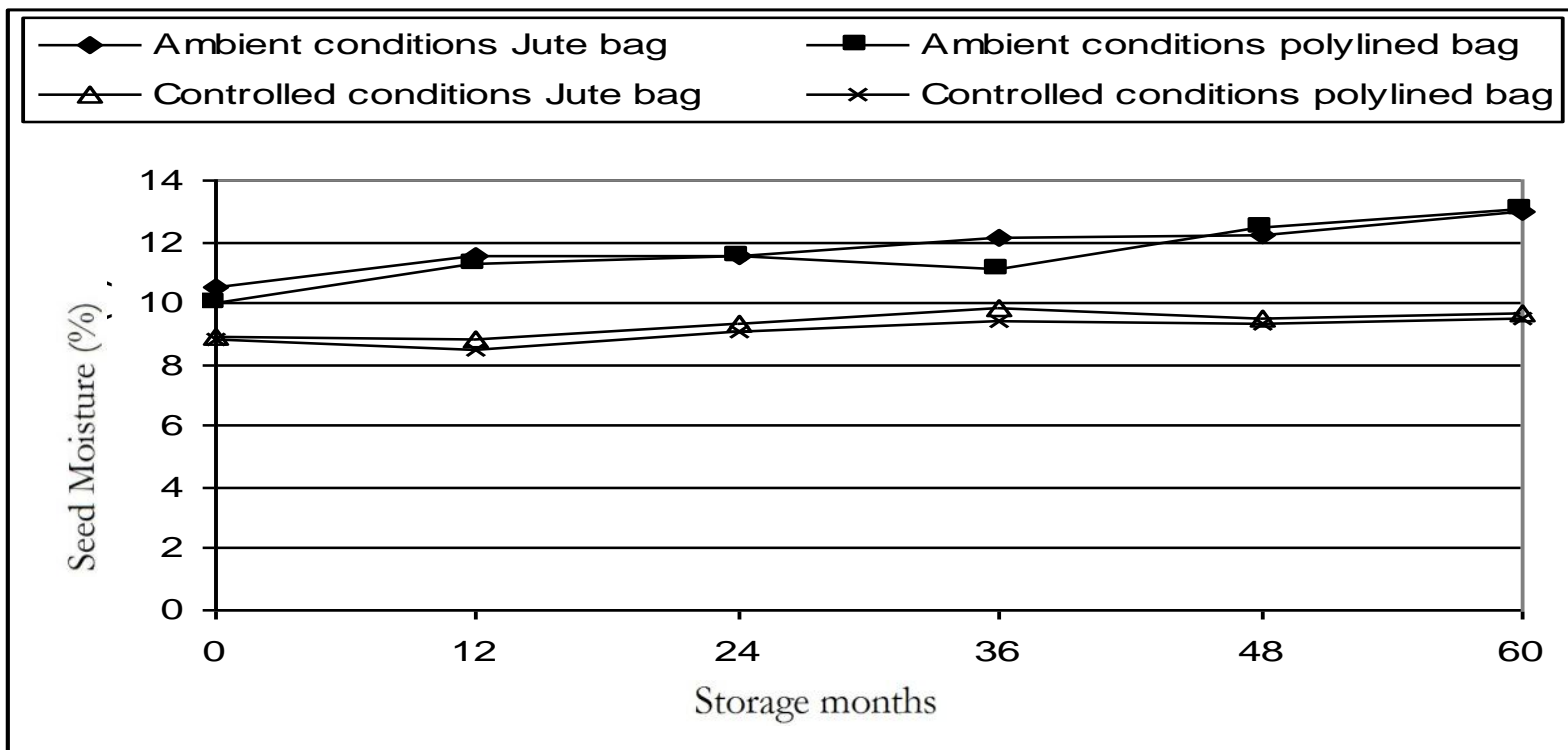

Figure 4. Moisture content of paddy seed in different storage treatments.

\subsection{Seed Mycoflora}

In all 16 fungi were found associated with paddy seed. The main fungi encountered on paddy seeds were Fusarium moniliforme, F. semitectum, F. graminearum, Drechslera oryzae, Curvularia lunata, C. oryzae, Alternaria alternate, $A$. padwickii, Aspergillus flavor, Penicillium sp. and Rhiropus stolonifer. Low to very low incidence of Aspergillus Niger, A. fumigatus, $A$. terreus, Cladosporium sp. and Curvularia clavata were also found associated with paddy seeds. The incidence of mycoflora decreased after 12 months of storage and increased thereafter under both the storage conditions. The fungal flora decreased by $58.4 \%$ under ambient storage conditions as against $15.7 \%$ under LTLH conditions on 12 months of storage after seed treatment. Maximum increase in the incidence of fungi was observed after 36 months of storage (39.6\%) under ambient storage conditions as against $114 \%$ increase at 48 months of storage under LTLH storage conditions. After 60 months of storage there was decrease in the fungal flora by $25 \%$ under ambient storage conditions and it increased by $35 \%$ under LTLH storage conditions.

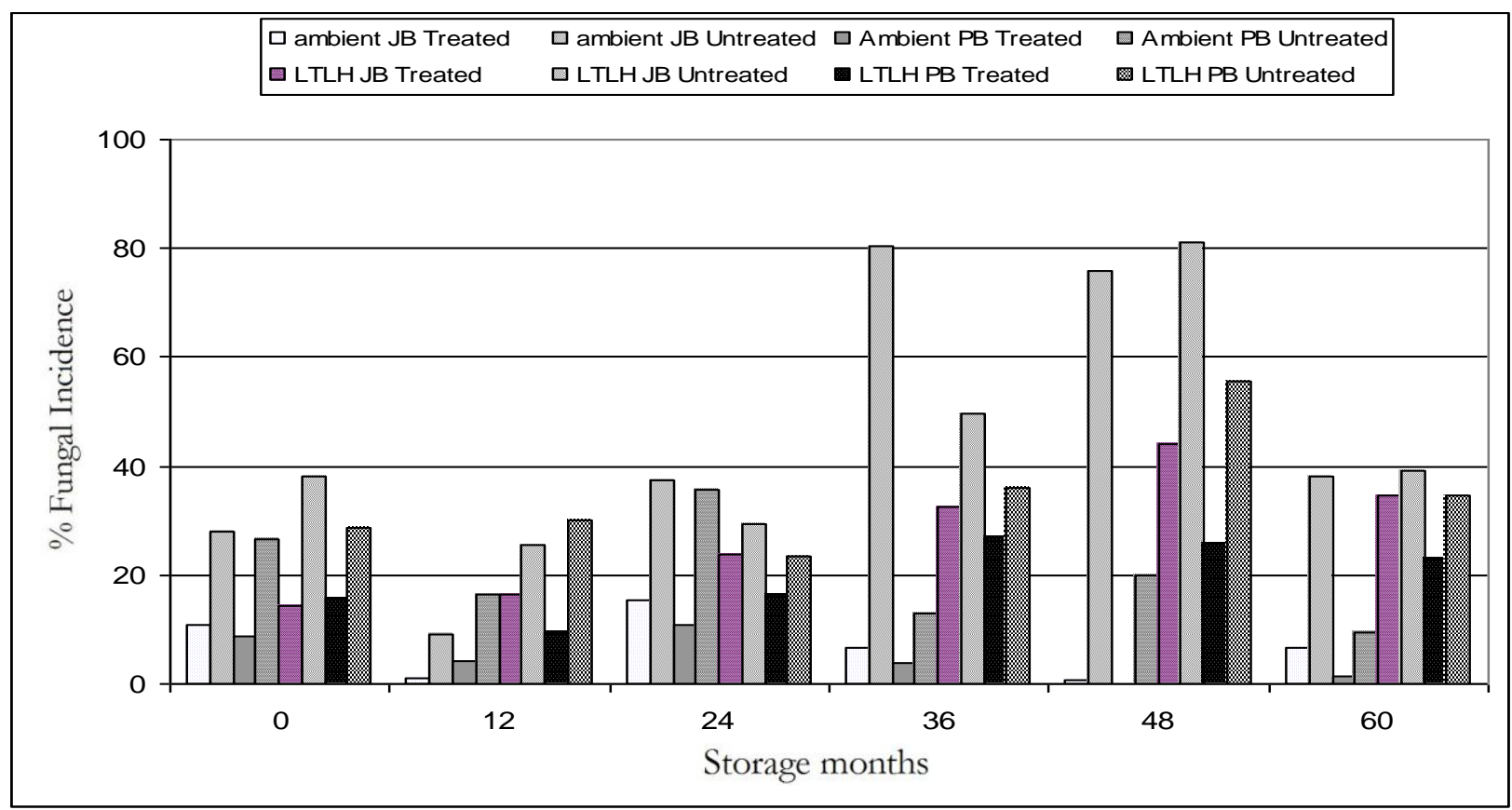

Figure 5. Effect of different storage treatments on fungal incidence during storage of paddy seed. 
Anuja Gupta

The incidence of mycoflora in 6A parental line was 54.8 percent as against 45.2 percent in $6 \mathrm{~B}$. Higher percent incidence of mycoflora was also recorded on seeds stored in jute bags $(60.9 \%)$ as against 39.1 percent incidence on seeds stored in polylined bags. Treatment with thiram/captan was found to be very effective in reducing the mycoflora incidence from 70.8 percent in untreated seed to 29.2 percent in treated seed during the entire storage period (Figure 5). The fungal load on paddy seed under ambient and LTLH storage conditions were 37.9 and $62.1 \%$, respectively. The incidence of mycoflora decreased up to 12 months of storage but thereafter it increased mainly due to the appearance of storage fungi like species of Aspergillus and Rhizopus.
Storage Technologies to Enhance Longevity

The incidence of Curvularia lunata and Alternaria padwickii was high on seeds stored under controlled conditions and low to very low on seeds stored under ambient conditions whereas incidence of Aspergillus flavus and Rhizopus stolonifer was high on seeds stored under ambient conditions as against seeds stored under LTLH conditions.

Seed treatment with thiram and captan could control 61 and $56 \%$ fungi, respectively as against untreated control (Figure 6). The efficacy of seed dressings was more pronounced under ambient storage conditions in both the type of containers, but under LTLH conditions the seed dressings appeared to have become inactive but the seeds were viable and hence the fungal flora flourished under LTLH storage conditions.

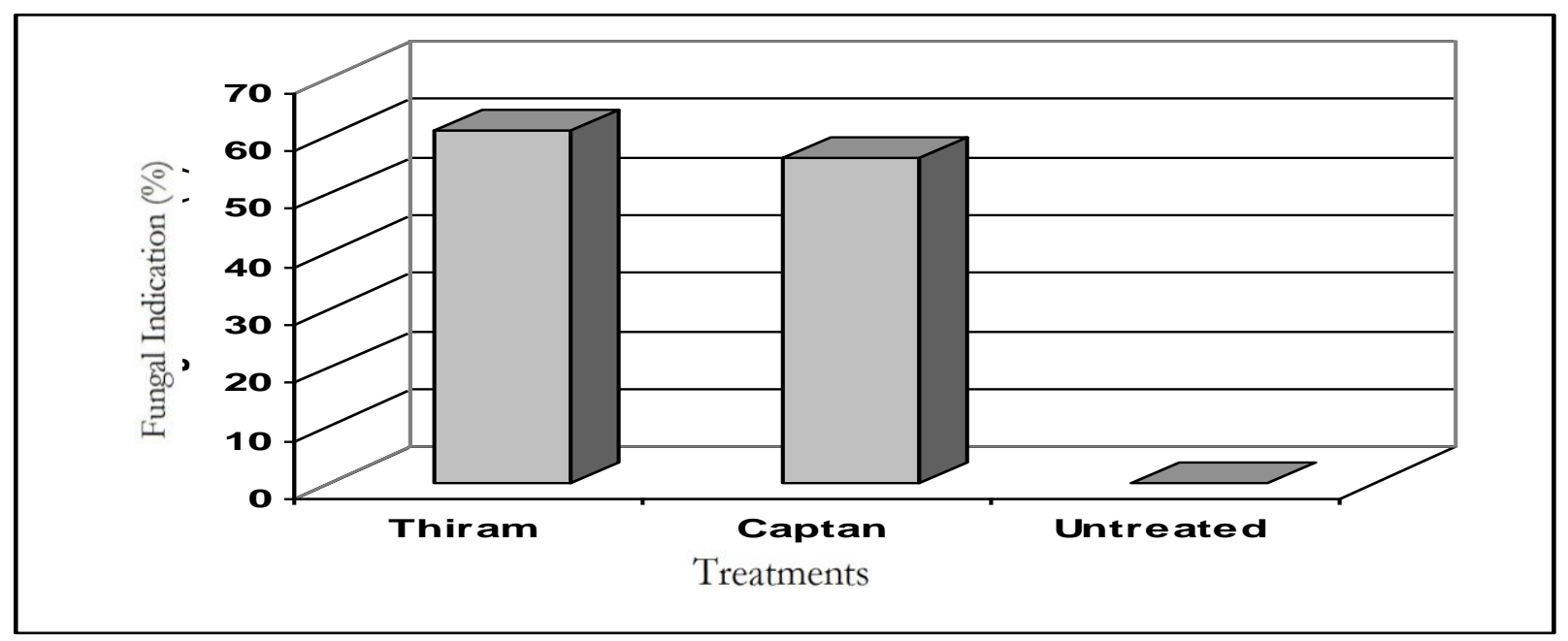

Figure 6. Efficacy of seed treatments on fungal load in paddy seed.

In earlier storage study in our laboratory on different cultivars of paddy, thiram and captan gave more than 96 and $90 \%$ control of seed mycoflora, respectively. The positive effect of the seed dressings has also been reflected in earlier works (Jakhar et al., 2003; Gupta and Aneja, 2004). Seed mycoflora has been recognized as an important factor responsible for deterioration in quality of seeds during storage (Gupta and Aneja, 2001). Control of seed mycoflora may be one of the reasons for maintenance of seed viability during storage. As long as the seed remained viable under LTLH conditions, fungi also remained viable and grew luxuriantly. Fungal growth is more in jute bags as compared to polylined bags probably because of higher seed moisture. Ghosh and Nandi (1986) observed that while one organism affects maximum loss in germination but maximum reduction in seedling growth was induced by another species. In some of the earlier studies (Paderes et al., 1997; Mazen et al., 1993) it has been reported that the seed mycoflora increases with the increase in seed moisture and results in seed rotting and loss in seed viability.

\subsection{Seedling Emergence in the Field}

Seedling emergence during Kharif 2002, 2003 and 2004 seasons was 43, 52 and 42 percent, respectively. The results of field emergence studies conducted during the three seasons revealed that as in seed germination, field emergence was also better in seeds of the parent $6 \mathrm{~B}$ $(51 \%)$ as against $49 \%$ in $6 \mathrm{~A}$. The seedling emergence of treated seed (55\%) was higher as against untreated seed (45\%). Though the seedling emergence got reduced over the storage time but it was higher in seeds stored under LTLH conditions $(57 \%)$ as against seed stored under ambient conditions (43\%). Seeds stored in polylined jute bags also exhibited higher seedling emergence (52\%) under field conditions than the seeds stored in jute bags $(48 \%)$.

\section{Conclusions}

The germination of seeds stored under low temperature and low humidity conditions was recorded $86.1 \%$ and in polylined jute bags $75.3 \%$ which was higher as compared to ambient condition (61.9\%) and in jute bags (72.8\%) after 60 months of seed treatment.

The storage of seeds in polylined containers and under controlled conditions was recorded superior as compared to storage of seeds in jute bags and under ambient conditions respectively.

The treated seeds showed $28.3 \%$ higher vigour Index I than untreated seeds during storage.

Higher variation in the moisture content was recorded in seeds stored under ambient conditions as compared 
Anuja Gupta

against seed stored under low temperature and low humidity (LTLH) conditions.

Treatment with thiram/captan was found to be very effective in reducing the mycoflora incidence from $70.8 \%$ in untreated seed to $29.2 \%$ in treated seed during the entire storage period.

Seeds stored in polylined jute bags exhibited higher seedling emergence $(52 \%)$ under field conditions than the seeds stored in jute bags $(48 \%)$

\section{References}

Abdul-Baki, A.A. and Anderson, J.D. 1973. Vigour determination in soybean by multiple criteria. Crop Sciences 10:31-34.

Agarwal, P.K. 1980. Relative storability of seeds of ten species under ambient conditions. Seed Research 8: 94-99.

Bhaskaran, N., Bharathi, A., Vanangamudi, K., Natesan, P., Natarajan, N., Jerlin, R. and Prabakar, K. 2005. Textbook on principles of Seed Production and Quality Control. Kalyani Publishers, India.

Chakravarthi, K. and Naravaneni, R. 2006. SSR marker based DNA fingerprinting and diversity study in rice. Africa Journal of Biotechnology 5(9): 684-688.

Dadlani, M. and Agarwal, P.K. 1983. Mechanism of soya bean seed deterioration. Plant Physiology and Biochemistry 10: 23-30.

Fairey, D.T. and Hamptan, J.G. 1997. Forage Seed Production. University of Cambridge, London, U.K.

FAO (Food and Agricultural Organization). 1995. Report of Food and Agricultural Organization.

Friere, M.S. and Mumford, P.M. 1986. The efficiency of a range of containers in maintaining seed viability during storage. Seed Science and Technology 14: 371-381.

Ghosh, J. and Nandi, B. 1986. Deteriorative abilities of some common storage fungi of wheat. Seed Science and Technology 14: 141-149.

Greve, J.E. and Van, S. 1983. Safe storage for small quantities of seed. Harvest 9: 5-10

Gowda, S.J. and Bhole, N.G. 1989. Prediction of relative germination of cereal seeds stored at different storage systems. Mysore Journal of Agricultural Sciences 23: $168-171$.

Gupta, A. 2003. Role of seed mycoflora in deterioration of soybean seed during storage under ambient conditions. In: Singh, D.P. (Ed.). Implications of Plant Diseases on Produce Quality. Kalyani Publishers, Ludhiana, India. pp. 85-96.

Gupta, A. 2007. Integrated management of seed health for prolonging seed storability in parental lines of pearlmillet (Pennisetum glaucum). Indian Journal of Agricultural Sciences 77(4): 212-219.
East African Journal of Sciences Volume 4 (2) 106-113

Gupta, A. and Aneja, K.R. 2001. Mycofloral spectrum during storage and its effect on seed viability of soybean [Glycine max (L.) Merrill] seeds under ambient conditions. Proceedings of National Academy of Sciences, India 71 B III \& IV. pp. 245253.

Gupta, A. and Aneja, K.R. 2004. Seed deterioration in soybean varieties during storage- Physiological attributes. Seed Research 32 (1): 26-32.

International Year of Rice. 2004. Rice in Life. Available at http//www.Fao.Ong/ag/inc/default.hm. (Accessed in April 2008.)

ISTA. 1999. International rules for seed testing. Seed Science and Technology 24: 333.

Jakhar, S.S., Duhan J.C. and Kharab, R.P.S. 2003. Effect of fungicide treatments and containers on pearlmillet seed storability. Indian Phytopathology 56: 484-485.

Kauraw, L.P. 1986. Effect of fungicides on the germination, root/shoot growth and incidence of seed borne pathogens in rice. Indian Phytopathology 39(4): 609-610.

Mazen, M.B., Abdel-Hafez, S.I., El-Kady, I.A. and ElMaghraby, O.M. 1993. Effect of level of relative humidity on fungi and germination capacity of paddy grains in Egypt. Qatar University Science Journal 13(1): 81-84.

Magune, J.D. 1962. Speed of germination: an aid in selection and evaluation for seedling emergence in vigour. Crop Sciences 2: 176-177.

Misra, A.K. and Dharam, V. 1991. Efficacy of fungicides XLVI: Effect of fungicidal seed treatment against heavy inoculum pressure of certain fungi causing discolouration of paddy seeds. Indian Phytopathology 43(2): 175-178.

Paderes, D.E., Mew, T.W. and Ilag, L.L. 1997. Influence of moisture content and length of storage on fungal invasion of paddy rice. Biotropia 10: 1-13.

Perry, D.A. 1978. Report of the vigour test committee. Seed Science and Technology 6: 159-181.

Sachan, I.P. and Agarwal, V.K. 1994. Efficacy of seed treatment of discoloured seeds of rice on seed-borne inoculum, germination and seedling vigour. Seed Research 22(1): 45-49.

Thijssen, M.H., Zewdie, B., Abrehman, B. and Baef, W.S. 2008. Farmers Seeds and Varieties supporting informal Seed Supply in Ethiopia. Wageningen, Wageningen International p.348.

Trawatha, S.E., Tekrony, D.M. and Hildebrand, D.M. 1995. Relationship of soybean seed quality to fatty acid and C-6 aldehyde levels during storage. Crop Sciences 35: 1415-1422. 